Data from 21 Cases with Severe Chronic Airways Obstruction

\begin{tabular}{|c|c|c|c|c|c|c|c|c|c|}
\hline \multirow[b]{2}{*}{$\begin{array}{l}\text { Case } \\
\text { No. }\end{array}$} & \multicolumn{3}{|c|}{ S.T.I.C. } & \multicolumn{3}{|c|}{$\alpha_{1}$-Antitrypsin } & \multicolumn{3}{|c|}{ Pulmonary Function } \\
\hline & $\begin{array}{l}\text { Venous } \\
\text { (Units*) }\end{array}$ & $\begin{array}{l}\text { Arterial } \\
\text { (Units*) }\end{array}$ & $\begin{array}{c}\% \\
\text { Difference }\end{array}$ & $\begin{array}{c}\text { Venous } \\
(\mathrm{mg} / 100 \mathrm{ml})\end{array}$ & $\begin{array}{l}\text { Arterial } \\
\left(\mathrm{mg}^{\prime} \mathbf{1 0 0} \mathrm{ml}\right)\end{array}$ & Difference & $\begin{array}{c}\text { VC } \\
\text { ( } \% \text { of Predicted) }\end{array}$ & $\begin{array}{c}\text { FRC } \\
\text { (\% of Predicted) }\end{array}$ & $\begin{array}{c}\mathrm{FEV}_{1} \\
(\% \text { of } \mathrm{VC}\end{array}$ \\
\hline $\begin{array}{r}1 \\
2 \\
3 \\
4 \\
5 \\
6 \\
7 \\
8 \\
9 \\
10 \\
11 \\
12 \\
13 \\
14 \\
15 \\
16 \\
17 \\
18 \\
19 \\
20 \\
21\end{array}$ & $\begin{array}{l}1.200 \\
1.043 \\
1.351 \\
1.209 \\
1.000 \\
1.444 \\
1.202 \\
1.563 \\
1.240 \\
1.400 \\
1.487 \\
1.651 \\
1.486 \\
1.284 \\
1.000 \\
1.875 \\
1.269 \\
1.382 \\
1.400 \\
1.265 \\
0.896\end{array}$ & $\begin{array}{l}1.133 \\
0.970 \\
1.285 \\
1.209 \\
0.805 \\
1.425 \\
1.135 \\
1.516 \\
1.178 \\
1.400 \\
1.487 \\
1.552 \\
1.425 \\
1.300 \\
1.105 \\
1.944 \\
1.169 \\
1.419 \\
1.438 \\
1.117 \\
0.969\end{array}$ & $\begin{array}{r}+5.6 \\
+7.0 \\
+4.9 \\
0 \\
+19.5 \\
+1.3 \\
+5.6 \\
+3.0 \\
+5.0 \\
0 \\
0 \\
+6.0 \\
+4.1 \\
-11.3 \\
-10.5 \\
-3.7 \\
+7.9 \\
-2.7 \\
-2.7 \\
+11.7 \\
-8.2\end{array}$ & $\begin{array}{l}180 \\
240 \\
200 \\
240 \\
200 \\
215 \\
191 \\
275 \\
240 \\
215 \\
225 \\
275 \\
240 \\
220 \\
215 \\
200 \\
235 \\
320 \\
240 \\
240\end{array}$ & $\begin{array}{l}180 \\
240 \\
200 \\
240 \\
170 \\
215 \\
194 \\
275 \\
240 \\
215 \\
225 \\
275 \\
240 \\
220 \\
240 \\
215 \\
235 \\
320 \\
225 \\
240\end{array}$ & $\begin{array}{c}0 \\
0 \\
0 \\
0 \\
+15 \cdot 0 \\
0 \\
-1 \cdot 6 \\
0 \\
0 \\
0 \\
0 \\
0 \\
0 \\
0 \\
-11 \cdot 6 \\
-7 \cdot 5 \\
0 \\
0 \\
+6 \cdot 3 \\
0\end{array}$ & $\begin{array}{r}84 \\
96 \\
85 \\
67 \\
111 \\
112 \\
100 \\
57 \\
74 \\
63 \\
63 \\
76 \\
56 \\
61 \\
102 \\
62 \\
62 \\
81 \\
56 \\
69 \\
32\end{array}$ & $\begin{array}{l}300 \\
230 \\
222 \\
198 \\
193 \\
193 \\
186 \\
185 \\
183 \\
177 \\
173 \\
175 \\
172 \\
168 \\
157 \\
156 \\
154 \\
146 \\
140 \\
127 \\
100\end{array}$ & $\begin{array}{l}29 \\
27 \\
33 \\
35 \\
29 \\
42 \\
40 \\
42 \\
31 \\
33 \\
56 \\
19 \\
44 \\
37 \\
66 \\
57 \\
27 \\
37 \\
35 \\
44 \\
33\end{array}$ \\
\hline
\end{tabular}

S.T.I.C. = Serum trypsin inhibitory capacity.
*Units $=$ mg trypsin inhibited by $1 \mathrm{ml}$ serum.

find any significant venoarterial difference in $\alpha_{1}$-antitrypsin activity or concentration in individuals with chronic obstructive lung diseases. In only two out of 21 patients with severe airways obstruction was there a significantly higher level of $\alpha_{1}$-antitrypsin in the venous blood than in the arterial blood as determined by two assay procedures. This suggests that a venoarterial difference in $\alpha_{1}$-antitrypsin concentration may occur in some unusual instances, but certainly not in most patients with airways obstruction, as reported by Woolcock et al. (1972).

Woolcock et al. postulated that their findings were possibly due to the binding of $\alpha_{1}$-antitrypsin to a protease during passage of the blood through the lungs, with alteration of the antigenic properties of $\alpha_{1}$-antitrypsin. In our experience binding of $\alpha_{1}$-antitrypsin to a protease is most effectively observed by a loss of the $\alpha_{1}$-antitrypsin activity (reduced S.T.I.C.) rather than by any decrease in $\alpha_{1}$-antitrypsin concentration as detected by immunological assays. Thus, one would expect an assessment of S.T.I.C. to be more sensitive for showing such venoarterial differences in $\alpha_{1}$-antitrypsin. Protease-inhibitor complexes usually have altered electrophoretic mobility but can be detected by immunological techniques (Ohlsson, 1971).

Thus, there is no significant venoarterial difference in $\alpha_{1}$ antitrypsin concentration in most individuals with severe obstructive lung diseases.

The author was supported by grant no. HL 13398 from the National Institutes of Health and by the Helen Galland Research Fund.

Requests for reprints should be addressed to: Dr. Jack Lieberman, City of Hope National Medical Center, 1500 East Duarte Road, Duarte, California 91010.

\section{References}

Lieberman, J. (1969). New England fournal of Medicine, 281, 279.

Lerman J. (1973). Medical Clinics of North America, 57,691.

Ohlsson, K. (1971). Scandinavian fournal of Clinical Lab Investigation, 28, 225

Woolcock, A. J., Green, W., and Crockett, A. (1972). British Medical fournal, 2, 134,

\title{
Prevention of Postoperative Deep Venous Thrombosis in Legs by Orally administered Hydroxychloroquine Sulphate
}

\author{
A. E. CARTER, R. EBAN
}

British Medical fournal, 1974, 3, 94-95

\section{Introduction}

Past observations (Carter et al., 1971) had suggested that hydroxychloroquine sulphate was an effective agent in reducing deep venous thrombosis in the leg after major surgery. Hydroxychloroquine sulphate is not an anticoagulant and is effective orally in safe doses. When given as a preoperative loading dose of $1,200 \mathrm{mg}$ in divided doses during the 24 hours preceding operation followed by $800 \mathrm{mg}$ daily in two divided doses until discharge from hospital the incidence of deep vein thrombosis, as assessed by ${ }^{125}$ I-tagged human fibrinogen leg scanning and venography was reduced from a control level of $16 \%$ to $5 \%$ in treated patients $(\mathrm{P}<0.005)$.

\section{Patients and Methods}

King Edward Memorial Hospital, London W13 9NU

A. E. CARTER, F.R.C.s., Consultant Surgeon

R. EBAN, F.F.R., Consultant Radiologist

Patient Selection.-Male and female patients over the age of 45 
TABLE I-Distribution of Patients by Sex and Age between Treated and Control Groups. Figures in Parentheses indicate Numbers in each Group who developed Thrombosis

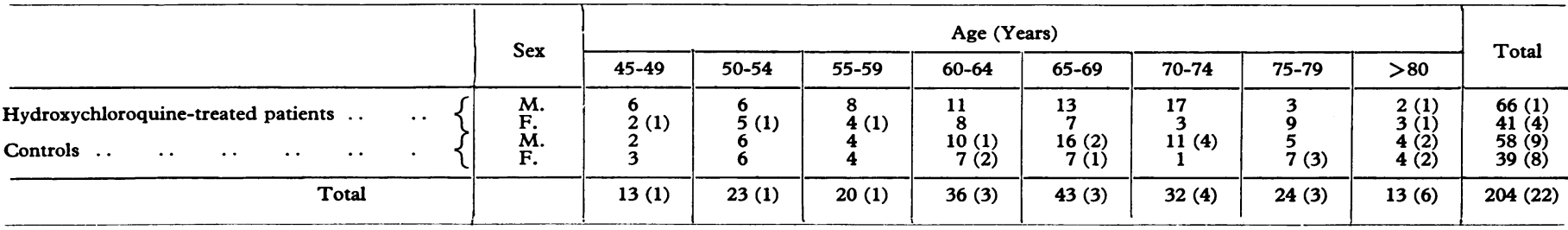

years admitted for non-emergency major surgery were allocated by the same random series used in previous reports to control and treated groups (Carter et al., 1971 ; Carter and Eban, 1973). Similarly, all patients with known cardiac or respiratory insufficiency, varicose veins, peripheral arterial disease, or a history of previous thrombotic episodes were excluded. No patient who had had major surgery within the previous six months was included.

A total of 204 patients were admitted to the trial: 107 (66 men and 41 women) were given hydroxychloroquine and 97 (58 men and 39 women) served as controls.

Dosage of Hydroxychloroquine Sulphate.-A dose of 1,200 mg hydroxychloroquine sulphate was given in three divided doses by mouth during the 24 hours before operation. Other $400-\mathrm{mg}$ doses were given at 12-hour intervals by mouth from the first day after operation until discharge from hospital. When a nasogastric suction tube was in place the dose of hydroxychloroquine was given by mouth at a suitable time immediately after an aspiration, and no further aspiration was performed for at least one hour.

Diagnosis of Deep Venous Thrombosis.-The method of Flanc et al. (1968) was used. Thyroid uptake of iodine was blocked with $100 \mathrm{mg}$ sodium iodide not less than one hour (intravenously) or more than 12 hours (orally) before giving $100 \mu \mathrm{C}$ 125I-tagged human fibrinogen (Radiochemicals Ltd.), which was given not less than one hour or more than six hours before operation. Both lower limbs were scanned with a Pitman 235 Isotope Localisator immediately before operation, just before leaving the recovery unit, and, thereafter, daily until discharge from hospital. Every patient in whom the scanning counts failed to fall progressively at each site in each leg was suspected of having a thrombosis at that site and had a phlebogram within 24 hours of the suspicion being raised. The diagnosis of thrombosis was made only when the thrombus was shown on the phlebogram.

Every patient in this series was ambulant on the day after operation. Those with intravenous infusions or other encumbrances were walked around their beds at least three times daily until ambulant without help.

\section{Results}

The distribution of cases by age and sex between the treatment and control groups is shown in table I. There were no significant differences in age between treated and control groups, and the male to female ratio was $1 \cdot 6: 1$. The distribution of cases in three operation sites is shown in table II. It should be noted that in men there was a preponderance of lower abdominal operation due to the large numbers of prostatectomies in the group.

TABLE II-Distribution of Type of Operation. Figures in Parentheses indicate Numbers in each Group who developed Thrombosis

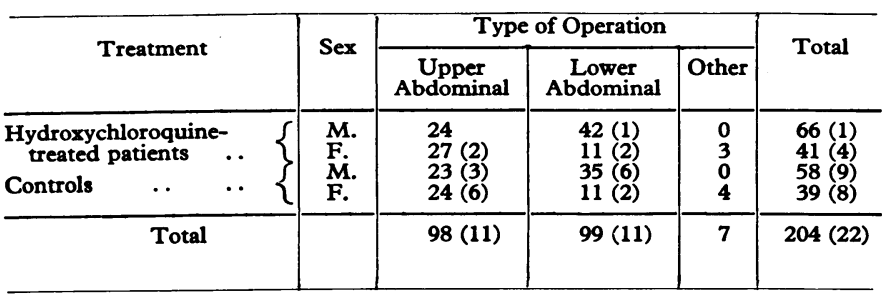

In men the incidence of thrombosis in the treated group was one in 66 cases and in the controls 9 in 58 cases. In women the incidence was four in 41 in the treated and eight in 39 in the control cases. There was no significant difference between men and women in the overall incidence of thrombosis $(10$ men and 10 women). The difference between the treated and control groups was significant $(P<0.005)$.

No statistical differences were observed between control and treated groups in the incidence of malignancy, type of anaesthetic, time spent on the operating table, the need for blood transfusion, or the amount of blood given. There were no differences between patients operated upon within 36 hours of admission and those in hospital for periods up to 20 days before operation. No patient had been confined to bed before operation.

In those cases for whom nasogastric suction was instituted there was no demonstrable statistical difference in the incidence of thrombosis attributable to nasogastric suction itself or to the number of days of its duration. No patient had nasogastric suction for more than four days.

No patient in either treated or control groups developed clinical or radiological signs of pulmonary embolism. Only one 82-year-old man (control group) developed an iliofemoral venous thrombosis.

\section{Discussion}

In a previous study (Carter et al., 1971) without the diagnostic refinement of isotope localization of thrombosis in the deep leg veins the evidence derived suggested that hydroxychloroquine sulphate could be a useful agent to prevent such thrombosis.

In this study using the technique of isotope localization originated by Flanc et al. (1968) a preoperative loading dose of $1,200 \mathrm{mg}$ hydroxychloroquine sulphate followed by $800 \mathrm{mg}$ daily in two divided doses produced a significant reduction in the incidence of postoperative deep venous thrombosis in the legs from a control level of $16 \%$ to a level in treated patients of $5 \%$.

The technique of administration by mouth has much to recommend it for simplicity. At this dosage hydroxychloroquine sulphate does not cause complications, and it seems to be a useful addition to present methods of prevention of unwanted thrombosis. It requires little effort to give, causes the patient no added distress, and would seem to be very suitable in heavily pressed surgical units.

This study was supported financially by Sterling Winthrop Research and Development who also provided the hydroxychloroquine sulphate (Plaquenil). We thank Dr. Sandra Savage of Sterling Winthrop for much help and advice and for the statistical analysis, the hospital's League of Friends who provided the Pitman 235 Isotope Localisator, and Sister Mary Livingstone and her staff who were responsible for much of the day-to-day organization of the study, especially the leg scanning.

\section{References}

Carter, A. E., Eban, R., and Perrett, R. D. (1971). British Medical fournal,

Carter, A. E., and Eban, R. (1973). British fournal of Surgery, 60, 681 Flanc, C., Kakkar, V. V., and Clarke, M. B. (1968). British fournal of
Surgery, 55, 752. 